\title{
PROPUESTA DE DESARROLLO TERRITORIAL RURAL PARA TABASCO.
}

\author{
Leticia Rodríguez Ocaña*, Concepción Reyes de la Cruz**, Juan Carlos Mandujano Contreras***.
}

\begin{abstract}
Rodríguez-Ocaña L., Reyes-De la Cruz C., MandujanoContreras J.C. Propuesta de desarrollo territorial rural para Tabasco. Hitos de Ciencias Económico Administrativas 2012;18 (50):23-28.
\end{abstract}

RESUMEN

La mayor parte de la población en situación de pobreza en México al igual que Latinoamérica se localiza en zonas rurales. En nuestro país 3 de cada 5 hogares son considerados pobres. El campo mexicano presenta rezago y marginación, con una producción heterogénea y polarizada, donde las condiciones de infraestructura de carreteras, todavía son un obstáculo para mejorar las condiciones de desarrollo de la población rural.

Con las propuestas del enfoque de desarrollo local sustentable, los aspectos de la «nueva ruralidad» son una alternativa para potencializar los recursos endógenos del campo tabasqueño. Esta propuesta para el desarrollo territorial rural integra la gestión por parte de los actores, donde la voluntad política es determinante para que se generen los empleos con actividades productivas sustentables, donde la gestión de servicios ambientales y la integración de cadenas de valor son la nueva dinámica en la aplicación de políticas públicas para el desarrollo del campo en Tabasco.

\author{
Rodríguez-Ocaña L., Reyes-De la Cruz C., Mandujano- \\ Contreras J.C. Rural territorial development proposal \\ for tabasco. Hitos de Ciencias Económico \\ Administrativas 2012;18 (50):23-28.
}

ABSTRACT

Most of the population in poverty situation in Mexico as well as in Latin America is located in rural areas. In our country 3 out of 5 households are considered poor. The Mexican countryside has backwardness and marginalized conditions, with a heterogeneous and polarized production, where the conditions of road infrastructure are still an obstacle to improve the development of the rural population.

With the proposals of local sustainable development approach, aspects of the «new rurality» are an alternative to potentiate endogenous resources of Tabasco field. This proposal for the rural land development integrates the management of the implicated, where political will is crucial in order to generate jobs with sustainable productive activities, where the management of environmental services and the integration of value chains are the new dynamic in implementing public policies for the development of the field in Tabasco.
Palabras clave: Desarrollo local sustentable. Desarrollo territorial rural. Estrategia de integración productiva.
Key words: Sustainable local development. Rural territorial development. Productive integration strategy.

DIRECCIÓN PARA RECIBIR CORRESPONDENCIA: Correo electrónico: concepcionreyesdelacruz@hotmail.com

\footnotetext{
* Maestra en Ciencias. Profesora-Investigadora. División Académica de Ciencias Económico Administrativas. Universidad Juárez Autónoma de Tabasco (UJAT).

* Doctora en Planificación de Empresas. Profesora-Investigadora. División Académica de Ciencias Económico Administrativas. Universidad Juárez Autónoma de Tabasco (UJAT).

** Maestro en Administración. Profesor-Investigador. División Académica de Ciencias Económico Administrativas. Universidad JuárezAutónoma de Tabasco (UJAT).
} 
$\mathrm{n}$ el entorno rural del país y en toda Latinoamérica, es en donde se localiza la mayor parte de la población en situación de pobreza, en México 3 de cada 5 hogares se encuentran en situación de pobreza, la gente del campo vive con una decima parte de lo que un hogar del medio urbano, lo hace. El campo mexicano se caracteriza por tener una heterogeneidad productiva y una alta polarización, es importante señalar que esto tiene un carácter estructural que ha influido en alcanzar mejor nivel de desarrollo, dando pauta al rezago y la marginación. La ubicación de las comunidades y la infraestructura carretera, impide que lleguen los recursos, y dificultan la articulación al mercado, siendo en la mayoría e los casos de autoconsumo; aunado al deterioro de sus recursos naturales, deforestación y pérdida de suelo que dan por resultado infertilidad o baja productividad del mismo.

Por generaciones la gente del campo sobrevivió como lo describe Chayanov en su teoría del campesinado, donde el trabajo de la familia era base de la economía y donde el valor del trabajo del campesino carece de valor monetario ya que lo que producía era para su consumo y sostenimiento de sus animales y solo una pequeña parte era para venta (CHAYANOV, 1985[1925]). Sin embargo, la modernidad y la globalización han hecho que el campesino se vea inmerso en una nueva ruralidad lo cual a obligado al campesino «o» a los habitantes, incluyendo a las mujeres de las zonas rurales, a tener una multiactividad tales como; jornaleros, donde buscan ocuparse en cultivos comerciales que les den ingresos monetarios, albañiles o comercio ambulante; generalmente migran a la cuidad a buscar mejores condiciones de vida. A este proceso de adaptación a una dinámica de mercado lo describe claramente Dominguez (1992), pues se observa claramente una diversificación productiva. Este autor hace referencia a las características adaptativas de las familias campesinas, evocando el concepto de Chayanov, donde la productividad de la «unidad doméstica depende de la autoexplotación familiar», misma que está en función de la intensidad del trabajo y de las necesidades acrecentadas del consumo de su familia.

El concepto de adaptación «se refiere a la manera en que la gente responde tanto a constreñimientos como a oportunidades en orden a sobrevivir en un medio físico y socio-económico particular», también se puede denominar "estrategias adaptativas», cuyo propósito es la maximización de la supervivencia. La economía campesina entonces, no es sólo un modo de vida sino un "modo de supervivencia», porque hablar del campesinado es hablar de «maneras de sobrevivir y mejorar uno mismo y su propia familia». Sobrevivir en la sociedad rural bajo el capitalismo significa acomodarse a los cambios estructurales más que resistirlos» (Domínguez, 1992).

En este sentido, es donde el ser humano busca desarrollarse, aprovechando el potencial endogeno, o sea directamente dependiente de la autoconfianza colectiva en la capacidad para inventar recursos, movilizar los ya existentes y actuar en forma cooperativa y solidaria, desde el propio territorio» (Boisier, 2004; 2008).

De a cuerdo al INEGI, Tabasco tiene una población de $2,238,603$. De esta un $43 \%$ es población rural que corresponden a 962599 habitantes. A diferencia del total del país en donde el $78 \%$ de la población es urbana y $22 \%$ es rural (INEGI. 2010). Se observa una vocación primordialmente agropecuaria, las condiciones geográficas son ideales para el desarrollo de las actividades primarias, la caracteristicas de sus suelos son generalmente fértiles.

El ultimo Censo nos muestra que el $28 \%$ de la población ocupada se dedica al sector primario, esto es, agricultura, ganadería y pesca, siguiendo como actividad predomínate el la ganadería extensiva, ocupando un $65 \%$ de la superficie estatal, con un sobre pastoreo del $50 \%$. Se cuenta con cerca de dos millones de cabezas, la ganadería bovina es una de las actividades más importantes en el Estado. 33 mil 785 productores de productos relacionados a esta actividad contribuyen de manera importante en la economía tabasqueña, como carne, leche entre otros.

Por otra parte, en lo que respecta a la agricultura los cultivos más comunes son cacao, yuca, maíz, caña de azúcar, plátano, arroz, sandía, coco y naranja (INEGI. 2010). Sin embargo, esta actividad enfrenta graves problemas, como la Moneleasis que está acabando con grandes extensiones dedicadas al cacao (Chacín 1981; Porras y Sánchez 1991); Aunado a lo anterior, los esquemas de apoyo hacia este sector son incipientes, 
acrecentándose la improductividad con el impacto de las inundaciones y sequias de los últimos años, donde el productor requiere considerar seguros para su producción como una estrategia de adaptación ante los impactos de este tipo de desastres. Cabe señalar, que no se omite el problema de antaño referido a la comercialización y distribución de los productos.

Existen esfuerzos Institucionales de aplicar programas y proyectos para disminuir la pobreza en el medio rural, pero no han sido suficientes, com por ejemplo: la siembra de palma de aceite, la participación en exposiciones nacionales de agroindustria, recursos económicos dirigidos a financiar el sector rural, y para disminuir el problema de la moneleasis. La situación es difícil y estructural y su solución coyuntural e integral.

Para este trabajo es importante considerar el concepto de desarrollo rural sustentable que aborda la gestión del desarrollo desde una perspectiva territorial. Su punto de partida es el análisis dinámico e integral de las dimensiones económica, sociocultural, ambiental y político institucional. En este sentido, el desarrollo rural es un proceso simultáneo e interrelacionado de producción, modernización y desarrollo social e institucional al interior de un territorio rural especifico. (Giordano, Paolo; Falconi, César; Sumpsi, José María, Agosto, 2007).

En este sentido se puede considerar el desarrollo rural como un paradigma complejo, que busca promover el bienestar de la sociedad rural, potenciando su contribución estratégica al desarrollo general de la sociedad. Su planteamiento es la formulación de estrategias e instrumentos de política que conduzcan al desarrollo territorial en regiones principalmente rurales, sobre todo en aquellas que buscan corregir desequilibrios de ingresos, mala distribución de la productos, patrones inadecuados de transporte y/o movimiento de bienes y servicios, así como del uso no sostenible de los recursos naturales.

La modernidad y la transformación del medio rural han traído consigo la diversificación económica y territorial, que ha forzado cambios y que valora todos los componentes del espacio, que debe de ser flexible, integrado y participativo, considerando las iniciativas de la comunidad (Sanz-Hernandez, A. 2001). Este enfoque da valor a lo paisajístico, cultural y ecológico, la diversificación productiva, el modelo productivo con una regulación ambiental, especialización flexible y los nuevos usos de la naturaleza (servicios ambientales). Para este tipo de emprendimiento se desarrolla una capacidad especial para generar empleos de multiples tipos y diversos ámbitos, lo que les concede un alto potencial como multiplicador económico a las comunidades, a través de la diversificación y ampliación del consumo local y la dinamización de la economía territorial (Sepúlveda 2003).

Debido a las fuerzas externas desde la globalización que exigen al productor que utilice métodos diversos para la producción de alimentos algunos de ellos para maximizar la producción y la nueva tendencia de los productos orgánicos y de calidad, productos que tiene un mercado en poblaciones conscientes del cuidado de su salud y también del consumo de productos elaborados con responsabilidad social.

Desde la perspectiva territorial el Desarrollo Rural se ubica en la perspectiva del Desarrollo Local Sustentable por estar basado en la equidad, distribución y acceso a los recursos; autonomía, democracia y ruptura de las relaciones de poder (ejemplo: políticos y de género), identificando a los actores o agentes en papeles y funciones «desde la base», esto es realizando acciones de gestión para generar las nuevas oportunidades de vida. En el mundo ya existen casos de éxito donde se promueve el desarrollo desde lo local como se observa en Argentina, Chile, Colombia y México, España, Italia y Francia, entre otros.

Sin embargo su enfoque humanista determina que la prioridad se centra en las personas, desde su transformación en agentes principales en el proceso de reestructuración. La estrategia necesita de agentes locales y la acción de empresarial, pero apoyada en un modelo microeconómico con características definidas: Recursos Endógenos (las ventajas comparativas del territorio) y Exógenos (complementarios), pequeña y mediana empresa, factor ecológico (como económico), y competencias administrativas y medios técnicos y financieros (Pérez Ramírez, B. y Carrillo Benito, E. 2000).

Lo anterior conlleva a considerar las ventajas competitivas, que deben de estar integradas a las 
condiciones de los factores productivos del área, la presencia y competitividad de todos los sectores relacionados, la existencia de un ambiente empresarial, y las políticas gubernamentales tendientes a potenciar los recursos locales (Méndez Gutiérrez, R. 1994).

La industria rural tiene como objetivo lograr una mayor diversificación de las economías rurales, basadas en la creación de pequeñas y medianas empresas (Comisión de las Comunidades Europeas, 1992), superando las tradicionales políticas de incentivos mediante la aceptación de un cierto reagrupamiento de las actividades, el apoyo directo a las PYMEs y el estímulo a la mejora cuantitativa y cualitativa de los servicios a la producción. Se trata, por tanto, de crear una densidad relacional mínima de condiciones que permitan fijar a las poblaciones y fortalecer a los servicios (Caetano, L. et al. 2001), lo que exige de un pacto territorial (Rodríguez Gutiérrez, F. 1996), así como de su ordenamiento. En este sentido (VazquezBarquero,2006) hace una contribución importante al considerar que la integración en cadenas de valor fortalecen la producción a nivel local, logrando impulsar las potencialidades endógenas en la región.

Para integrar estrategias que contribuyan a mejorar la situación de pobreza se requiere de esfuerzos conjuntos entre todos los actores como lo señalan Sepúlveda, Rodríguez, Echeverri y Portilla, M. (2003). Su importancia radica en las decisiones de política publica que considere respecto a la diversidad y derecho a la territorialidad. Solo así la planeación del desarrollo rural con enfoque local responderá a un modelo estratégico, para mejorar la situación del medio rural.

\section{Conclusiones.}

En Tabasco el territorio rural presenta potencialidades de desarrollo, debido a la presencia de vastos recursos naturales, conocimiento tradicional, riqueza cultural y fuerza laboral. Pero para alcanzar el bienestar social y la sustentabilidad del desarrollo implica, conocimiento, suma de recursos, creación de sinergias y voluntad política. Por ello, se propone una estrategia para el desarrollo rural de largo plazo, que fomente la participación social y gubernamental para implementar prácticas y proyectos productivos ambientalmente amigables, que conlleven al establecimiento de comunidades rurales solidas, con mejor calidad de vida.
La estrategia de desarrollo rural con enfoque local que se propone tiene los siguientes elementos básicos:

$\checkmark \quad$ El éxito de una estrategia de desarrollo local depende en gran medida de la capacidad local para crear condiciones que faciliten la creación de empleos.

$\checkmark \quad$ Voluntad política y participación de todos los actores a nivel local para aprovechar sus potencialidades.

$\checkmark$ Crear un modelo de participación ciudadana responsable para el bienestar social y la sustentabilidad ambiental.

$\checkmark$ Crear una red de comunidades rurales con disposición y capacitación para llevar a cabo proyectos sociales, económicos y productivos sustentables.

$\checkmark$ Establecer esquemas de colaboración interinstitucionales (universidades y centros de investigación), con dependencias estatales, federales y municipales para la concurrencia de recursos y programas de desarrollo con enfoque de sustentabilidad. 


\section{REFERENCIAS}

Boisier, S. (2008). Territorio, estado y sociedad en Chile. La dialéctica de la descentralización: entre la geografía y la gobernabilidad. Tesis Doctoral www. eumed.net/tesis/2008/sbe/sbe.zip. Recuperado el día 27 de febrero 2012.

Chayanov, A.V. 1985). La organización de la unidad económica campesina. Buenos Aires: Nueva Visión.

Torres, F. y Delgadillo, J. (2009). Hacia una política territorial del desarrollo rural de México. Convergencia. Revista de Ciencias Sociales, Núm. Mayo-Agosto, pp. 107-131. Recuperado el 26 de febrero de 2012, de http://redalyc.uaemex.mx/pdf/105/10511169005.pdf.

Domínguez, R. (1992). Campesinos, mercado y adaptación. Una propuesta de síntesis e interpretación desde una perspectiva interdisciplinar. Noticiario de historia agraria, Núm. 3 (1992-1). España: Universidad de Cantabria.

Giordano, P., Falconi, C., y Sumpsi, J. M. (2007). Desarrollo Rural y Comercio Agropecuario en América Latina yel Caribe. (1 ra ed.). BuenosAires: -BID-INTAL.

INEGI. Censo de Población y Vivienda (2010). Disponible en: http://www.inegi.org.mx/sistemas/ mexicocifras/default.aspx?e=27. Recuperado el 25 de febrero de 2012.

Sanz, A. (2001). Desarrollo rural ¿Ocio o necesidad? Disponible en: http://www.5campus.com/leccion/ desarural. Recuperado el 27 de febrero de 2012.
Pérez, B. y Carrillo, E. (2000). El modelo teórico del desarrollo local. Madrid: Federación Andaluza de Municipios y Provincias-ESIC.

Méndez, R. (1994). Sistemas Productivos Locales y Políticas de Desarrollo Rural. Estudios Regionales, Núm. 39.

Caetano, L. et al. (2001). Redes de informaçao e desenvolvimento rural: impacto na reorganizaçao dos territórios rurais frágeis da regiao centro interior de Portugal.

Rodríguez, F. (1996). El desarrollo local, una aplicación geográfica. Exploración teórica e indagación sobre su práctica. Ería.

Vázquez-Barquero, A. (2006). Surgimiento y transformación de clusters y milieus en los procesos de desarrollo. EURE (Santiago) [online], Vol.32, Núm.95 [citado 2012-03-01], pp. 75-93. Disponible en: http:// www.scielo.cl/scielo.php? Recuperado el 28 de febrero de 2012.

Sepúlveda, S. (2003). Nueva institucionalidad para el desarrollo rural de América Latina y el Caribe en el contexto actual. San José, Costa Rica: IICA.

Sepúlveda, S., Rodríguez, A., Echeverri, R., y Portilla, M. (2003). El enfoque territorial de desarrollo rural. San José, Costa Rica: IICA. 


\section{Oferta Educativa de Licenciaturas}

Divisiőn Académica de Ciencias Blolögicas

Licenciatura en Biología

Licenciatura en Gestión Ambiental

Licenciatura en Ingeniería Ambiental

Divisiő́n Académica de Ingeniería y Árquitectura

Ingeniería Civil

Ingeniería Eléctrica y Electrónica

Ingeniería Mecánica Eléctrica

Ingeniería Química

Licenciatura en Arquitectura

Divisiön Acadëmica de Ciencias Sociales y Humanidades

Licenciatura en Derecho (escolarizado y sistema abierto)

Licenciatura en Historia

Licenciatura en Sociología

Divisiő́n Acadêmica de Ciencias Econōmice Administrativas

Licenciatura en Administración (escolarizado y a distancia)

Licenciatura en Contaduría Pública (escolarizado y a distancia)

Licenciatura en Economía

Licenciatura en Mercadotecnia

Divisiớn Académica de Clencias Agropecuarias

Ingeniería en Acuacultura

Ingeniería en Agronomía

Ingeniería en Alimentos

Licenciatura en Medicina Veterinaria y Zootecnia

Divisiőn Académica Multidisciplinaria de Gomalcalco

Licenciatura en Enfermería

Licenciatura en Médico Cirujano

Licenciatura en Atención Prehospitalaria y Desastre

Licenciatura en Rehabilitación Física
Divisiőn Académica de Educaciőn y Artes

Licenciatura en Ciencias de la Educación

Licenciatura en Comunicación

Licenciatura en Desarrollo Cultural (sistema abierto)

Licenciatura en Idiomas

Técnico Superior Universitario en Enseñanza de Inglés

Técnico Superior Universitario en Música

Divisiő́n Académica de Ciencias de la Salud

Licenciatura en Médico Cirujano

Licenciatura en Cirujano Dentista

Licenciatura en Psicología

Licenciatura en Nutrición

Licenciatura en Enfermería

Enfermería (semipresencial) Nivel Técnico

Curso complementario de Licenciatura en Enfermería

(a distancia y semipresencial)

Divisiőn Académíca de Informática y Sistemas

Licenciatura en Informática Administrativa

Licenciatura en Sistemas Computacionales

Licenciatura en Telemática

Licenciatura en Tecnologías de la Información

Divisiőn Académica de Ciencias Bảsicas

Licenciatura en Ciencias Computacionales

Licenciatura en Física

Licenciatura en Matemáticas

Licenciatura en Química

Licenciatura en Actuaría

Divisiő́n Académica Multidisciplinaria de los Ríos

Ingeniería en Acuacultura

Licenciatura en Administración

Ingeniería en Alimentos

Licenciatura en Informática Administrativa

Licenciatura en Derecho 